\title{
25 Research Square \\ Clinical Significance and Genetic Characteristics in HER2 Low Expression Tumors of Hormone Receptor Positive Breast Cancer Patients
}

\section{Mengdi Chen}

Shanghai Jiao Tong University Medical School Affiliated Ruijin Hospital

Deyue Liu

Shanghai Jiao Tong University Medical School Affiliated Ruijin Hospital

\section{Weilin Chen}

Shanghai Jiao Tong University Medical School Affiliated Ruijin Hospital

\section{Weiguo Chen}

Shanghai Jiao Tong University Medical School Affiliated Ruijin Hospital

\section{Kunwei Shen}

Shanghai Jiao Tong University Medical School Affiliated Ruijin Hospital

\section{Jiayi Wu}

Shanghai Jiao Tong University Medical School Affiliated Ruijin Hospital

\section{Li Zhu ( $\nabla$ zhuli8@yeah.net)}

Ruijin Hospital『Shanghai Jiao Tong University School of Medicine https://orcid.org/0000-0002-92945727

\section{Research article}

Keywords: breast cancer, HER2 low, 21-gene, recurrence score, hormone receptor positive

Posted Date: August 4th, 2021

DOI: https://doi.org/10.21203/rs.3.rs-752911/v1

License: (c) (1) This work is licensed under a Creative Commons Attribution 4.0 International License. Read Full License 


\section{Abstract}

\section{Background}

Human epidermal growth factor receptor 2 (HER2) low expressed breast cancer was considered as a distinct subtype different from HER2 negative tumors. We investigated the clinicopathological features and recurrence score (RS) of HER2-low and HER2- patients and their prognostic value in hormone receptor (HR) positive breast cancer.

Methods

A total of 2,099 HR-positive primary female breast cancer patients between Jan 2009 and Jan 2019 were collected and tumors with immunohistochemistry $1+$ or $2+$ with negative in situ hybridization results was defined as HER2 low. We retrospectively compared the clinical and genetical features of HER2-low $(n=$ $1,732)$ and HER2- $(n=367)$ breast cancer and theirs impacts on disease-free survival (DFS).

Results

The HER2 low tumors had a higher ratio of concurrent estrogen receptor (ER) high expression than HER2patients both at protein level (ER > 90\%: $78.2 \%$ vs $58.6 \%, p<0.01$ ) and mRNA level (Spearman $R=0.5$ vs 0.3). Analysis about DFS showed no significant difference between HER2 negative and low subgroups (5year DFS: $92.3 \%$ vs $93.3 \%, p=0.83$ ). However, RS range (cut-off: 18 and 30 ) didn't maintain its predictive value in HER2 low patients $(p=0.11)$ unlike that in HER2- group $(p=0.003)$. Further research for respective gene suggested that proliferation related genes performed well in predicting DFS in HER2patients but lost its value in HER2 low group ( $p$ for interaction < 0.01 ). Contrarily, higher HER2 module was associated with worse DFS only in HER2 low patients $(p=0.04)$.

Conclusion

Our study found that HER2 low expression couldn't be a prognostic factor in HR + patients. HER2-low patients had a higher proportion of ER high expressed tumors than HER2- ones did. The 21-gene assay and its proliferation module might be less applicable to HER2-low patients compared with HER2-patients.

\section{Introduction}

Human epidermal growth factor receptor 2 (HER2) was an important prognostic and predictive factor for breast cancer. In general, HER2 positive breast cancer could benefit from anti-HER2 agents such as trastuzuamb, pertuzumab, lapatinib, etc ${ }^{1-3}$, while HER2 negative tumors couldn't. In addition to this conventional binary classification, evolving evidence has indicated HER2 intratumor and intertumor heterogeneity ${ }^{4-6}$. Cases with immunohistochemistry $(\mathrm{IHC}) 1+$ or $2+$ with negative in situ hybridization (ISH) results, which had been categorized as HER2 negative before, were re-classified into a distinct new subtype: HER2-low breast cancer ${ }^{7}$. 
About $45 \%-55 \%$ breast cancers were HER2 protein low expression ${ }^{8}$. So far, studies about these tumors were insufficient for clinicians to differentiate them from other traditional subtypes. Previous evidence also contradicted with each other when investigating the survival outcomes of these patients ${ }^{9-12}$. The result of NASBP B-47 suggested that HER2-targeted therapy didn't produce effect on HER2 low breast cancer $^{13}$ and this subset was treated as luminal-like or triple negative subtype according to the hormone receptor (HR) status. However, the recent emergence of novel anti-HER2 agents brought striking benefit to HER2 low metastatic breast cancer ${ }^{14,15}$ possibly due to the bystander killing effect ${ }^{16}$. Therefore, further investigation might change the pattern of diagnosis and treatment of HER2-low breast cancer.

Approximately $50-80 \%$ of traditional HER2-negative breast cancer were HR-positive simultaneously ${ }^{11,17}$. Importantly, previous analysis suggested that the difference between HER2 low expression and HER2 negativity had more clinical impact in HR + breast cancer than in triple negative breast cancer ${ }^{17}$. In the past two decades, the 21 -gene recurrence-score $(R S)^{18}$ has provided prognostic information for HR+/HER2- patients in clinical practice, including HER2-low tumors. Whether low expression of HER2 gene or protein would influence the predictive value of the clinicopathological factors and RS has been never investigated before. Furthermore, two HER2 amplification related genes, growth factor receptor bound protein 7 (GRB7) and HER2, were important components of the RS assay, and they might play a different role in tumors with HER2 low status or complete HER2 negativity. Since HER2-low breast cancer began to come into sight as a separate entity, it is necessary to re-evaluate the prognostic roles of traditional features and the use of RS in HR+/HER2-low breast cancer patients.

In our study, we attempted to make a comparison of basic clinicopathological factors between HER2-low and HER2- breast cancer patients. We also analyzed the prognostic value of the RS for the survival outcome of these two subgroups.

\section{Patients And Methods}

\section{Patients}

In total, clinical data of 2,099 HR-positive primary female breast cancer patients between Jan 2009 and Jan 2019 was collected from Shanghai Jiao Tong University Breast Cancer Data Base (SJTU-BCDB). Inclusion criteria were listed as follows: (1) estrogen receptor (ER) positivity with $\geq 1 \%$ immunoreactive tumor cell nuclei determined by IHC test ${ }^{19}$; (2) detailed IHC and ISH results of HER2; (3) record of a 21 gene test. The median follow-up time was 50.19 (range 2.54-120.00) months.

\section{HER2 Status}

HER2 negativity was defined as score 0 of IHC. HER2-low expression was defined as IHC $1+$ or $2+$ combined with non-amplification of HER2 gene on fluorescence in situ hybridization. According to American Society of Clinical Oncology (ASCO) guidelines ${ }^{20}$, HER2 non-amplification was 
HER2/centromeric probe for chromosome 17 (CEP17) ratio < 2.0 with average HER2 gene copy number < 6.0 signals/cell, or average HER2 gene copy number $<4.0$ signals/cell regardless of the ratio.

21-gene Assay Testing

The 21-gene tests were performed using formalin-fixed, paraffin-embedded tissue. Hematoxylin and eosin-stained slides were deparaffinized into two 10 $\mu$ m unstained sections using xylene followed by ethanol ${ }^{21}$. RNA was extracted using the RNeasy FFPE kit (QIAGEN, Hilden, Germany). Total RNA content was quantified after confirmed the absence of DNA contamination. Then, gene-specific reverse transcription was conducted followed by standardized quantitative reverse transcriptase-polymerase chain reactions (RT-PCR) in 96-well plates with Applied Biosystems (Foster City, CA) 7500 Real-Time PCR system. The PCR cycling went as follows: $95 \circ \mathrm{C}$ for $10 \mathrm{~min}$ for one cycle, $95 \circ \mathrm{C}$ for $20 \mathrm{~s}$, and $60 \circ \mathrm{C}$. We used 18 and 30 as the cutoff of RS range ${ }^{18}$.

\section{Statistical Analysis}

We used disease-free survival (DFS) as our endpoint. DFS was defined as the length of time from the first treatment for breast cancer to the time of first event as follows: local, regional or distant recurrence, contralateral breast cancer, secondary malignancy or death as a result of any cause. The Kaplan-Meier survival analysis, univariate and multivariate Cox regression analysis was performed in patients according to different genetic risks and HER2 expression. All our tests were performed using R Studio version 1.2.5019 based on $\mathrm{R}$ version 4.0.3.

\section{Results}

\section{Baseline characteristics according to HER2 expression}

The majority of 2,099 HR positive cases were HER2 low expressed tumor $(n=1,732,82.5 \%)$. No significant difference was found when comparing the age, menopause status, histological grade, progesterone receptor (PR status, American Joint Committee on Cancer (AJCC) stage, RS range and treatment after surgery between HER2-low and HER2 negative subgroups (Table 1). The HER2 negative subgroup had a higher proportion of specific pathologic types beyond invasive ductal and lobular cancer $(16.1 \%$ vs $10.5 \%, p=0.01)$ and tumors with high histologic grade $(p=0.02)$. We also divided ER IHC expression into two categories based on the median percentage of $90 \%$. The HER2 low tumors showed a higher ratio of concurrent ER high expression than HER2 negative patients $(78.2 \%$ vs $58.6 \%, \mathrm{p}<0.01)$. 
Table 1

Basic Characteristics of 2,099 HR + breast cancer patients from SJTU-BCDB

\begin{tabular}{|c|c|c|c|}
\hline Characteristics & $\begin{array}{l}\text { HER2 negative } \\
\mathrm{n}=367\end{array}$ & $\begin{array}{l}\text { HER2 low } \\
n=1,732\end{array}$ & p-value \\
\hline $\begin{array}{l}\text { Age } \\
\leq 50 \\
>50\end{array}$ & $\begin{array}{l}110(30.0) \\
257(70.0)\end{array}$ & $\begin{array}{l}562(32.4) \\
1,170(67.6)\end{array}$ & 0.39 \\
\hline $\begin{array}{l}\text { Menopause status } \\
\text { Premenopausal } \\
\text { Postmenopausal }\end{array}$ & $\begin{array}{l}123(33.5) \\
244(66.5)\end{array}$ & $\begin{array}{l}607(35.0) \\
1,125(65.0)\end{array}$ & 0.61 \\
\hline $\begin{array}{l}\text { Pathology } \\
\text { IDC } \\
\text { ILC } \\
\text { others }\end{array}$ & $\begin{array}{l}294(80.1) \\
14(3.8) \\
59(16.1)\end{array}$ & $\begin{array}{l}1,478(85.3) \\
72(4.2) \\
182(10.5)\end{array}$ & 0.01 \\
\hline $\begin{array}{l}\text { Grade } \\
\text { I } \\
\text { II } \\
\text { III } \\
\text { Unknown }\end{array}$ & $\begin{array}{l}36(9.8) \\
173(47.1) \\
77(21.0) \\
81(22.1)\end{array}$ & $\begin{array}{l}147(8.5) \\
1,027(59.3) \\
312(18.0) \\
246(14.2)\end{array}$ & 0.02 \\
\hline $\begin{array}{l}\text { ER positivity(\%) } \\
<90 \\
\geq 90\end{array}$ & $\begin{array}{l}152(41.4) \\
215(58.6)\end{array}$ & $\begin{array}{l}377(21.8) \\
1355(78.2)\end{array}$ & $<0.01$ \\
\hline $\begin{array}{l}\text { PR } \\
\text { Positive } \\
\text { Negative }\end{array}$ & $\begin{array}{l}313(85.3) \\
54(14.7)\end{array}$ & $\begin{array}{l}1,540(88.9) \\
192(11.1)\end{array}$ & 0.06 \\
\hline $\begin{array}{l}\mathrm{Ki} 67(\%) \\
<20 \\
\geq 20\end{array}$ & $\begin{array}{l}213(58.0) \\
154(42.0)\end{array}$ & $\begin{array}{l}951(54.9) \\
781(45.1)\end{array}$ & 0.30 \\
\hline
\end{tabular}

Abbreviation: IDC, invasive ductal carcinoma; ILC, invasive lobular carcinoma; ER, estrogen receptor; PR, progesterone receptor; RS, recurrence score; Al, aromatase inhibitor; SERM, selective estrogen receptor modulator; OFS, ovarian function suppression. 


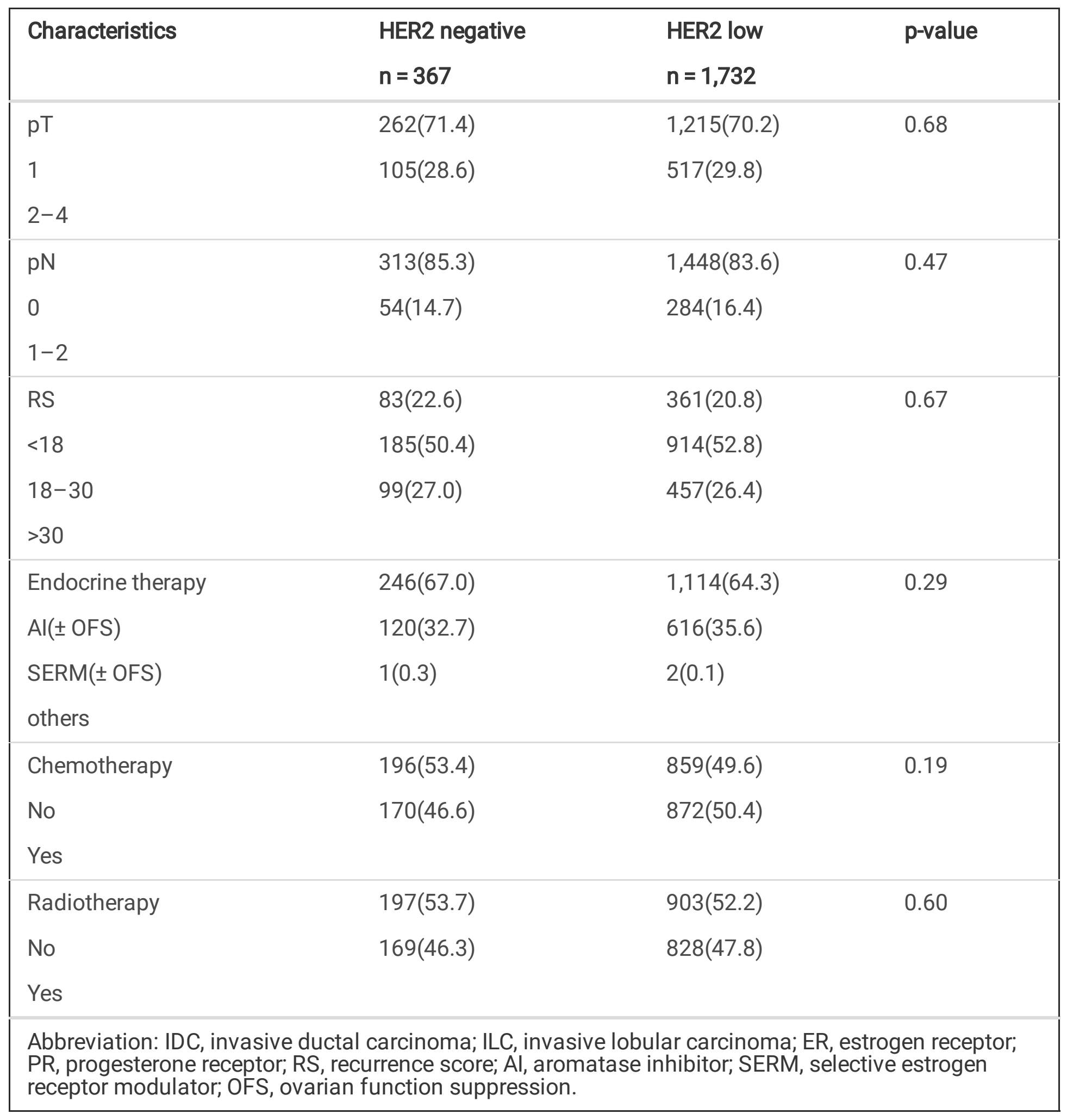

\section{The survival outcomes of patients according to different HER2 status}

A total of 146 DFS events happened during the follow-up period (33 and 123 in HER2 negative and low subgroups respectively). The Kaplan-Meier curves (Fig. 1) revealed no significant difference between HER2 negative and low subgroups in HR + patients. We further performed survival analyses according to 
different RS, and the subpopulation treatment effect pattern plot (STEPP) analysis ${ }^{22}$ (Fig. 3) showed that in patients with RS > 30, HER2 low subgroup showed a better DFS than HER2 negative subgroup. We compared the predictive value of RS in HR + patients with different HER2 status (Fig. 2). Surprisingly, in HER2 negative patients, the Kaplan-Meier curves showed significant different survival outcomes between patients with high risk and those with low/intermediate risk $(p=0.003)$. However, the recurrence score was not significantly correlated with survival outcomes in HER2 low patients $(p=0.11)$.

\section{Univariate And Multivariate Analysis Of Clinicopathological Predictors For Dfs}

We further investigated the impact of clinicopathological factors on DFS in subgroups divided by HER2 status respectively (Table 2). In HER2 negative population, higher $\mathrm{pN}$ grade (hazard ratio $=2.59,95 \% \mathrm{Cl}$ $1.08-6.26, p=0.03$ ) and $\mathrm{RS}>30$ (hazard ratio $=2.39,95 \% \mathrm{Cl} 1.14-5.04, \mathrm{p}=0.02$ ) was associated with worse survival outcomes after adjustment. However, in patients with HER2 low tumors, higher RS and pN stage lost their prognostic value both in univariate and multivariate analysis. 
Table 2

The impact of clinicopathological factors on DFS according to HER2 status

\begin{tabular}{|c|c|c|c|c|}
\hline Factors & Univariate Analysis & p-value & Multivariate Analysis & $\mathrm{p}$-value \\
\hline \multicolumn{5}{|l|}{ HER2 negative } \\
\hline Age(y) & $1.08(0.51-2.66)$ & 0.85 & & \\
\hline \multicolumn{5}{|l|}{$>50$ vs $\leq 50$} \\
\hline Menopause & $1.37(0.65-2.88)$ & 0.42 & & \\
\hline \multicolumn{5}{|l|}{ Post vs Pre } \\
\hline Grade & $1.67(0.76-3.65)$ & 0.20 & & \\
\hline \multicolumn{5}{|l|}{ III vs I-II } \\
\hline ER positivity(\%) & $0.46(0.21-1.02)$ & 0.06 & $0.53(0.23-1.20)$ & 0.13 \\
\hline \multicolumn{5}{|l|}{$\geq 90$ vs $<90$} \\
\hline PR status & $0.39(0.18-0.81)$ & 0.01 & $0.62(0.28-1.39)$ & 0.24 \\
\hline \multicolumn{5}{|l|}{ Pos vs Neg } \\
\hline Ki67 positivity(\%) & $1.68(0.82-3.43)$ & 0.16 & & \\
\hline \multicolumn{5}{|l|}{$\geq 20$ vs $<20$} \\
\hline pT & $1.99(0.98-4.01)$ & $<0.01$ & $1.51(0.70-3.24)$ & 0.29 \\
\hline \multicolumn{5}{|l|}{$2-4$ vs 1} \\
\hline $\mathrm{pN}$ & $2.84(1.24-6.49)$ & 0.01 & $2.59(1.08-6.26)$ & 0.03 \\
\hline \multicolumn{5}{|l|}{$\geq 1$ vs 0} \\
\hline RS & $3.10(1.56-6.17)$ & $<0.01$ & $2.39(1.14-5.04)$ & 0.02 \\
\hline \multicolumn{5}{|l|}{$>30$ vs $\leq 30$} \\
\hline Chemotherapy & $1.44(0.72-2.86)$ & 0.30 & & \\
\hline \multicolumn{5}{|l|}{ No vs Yes } \\
\hline \multicolumn{5}{|l|}{ HER2 low } \\
\hline Age(y) & $0.90(0.62-1.31)$ & 0.60 & & \\
\hline \multicolumn{5}{|l|}{$>50$ vs $\leq 50$} \\
\hline Menopause & $0.91(0.63-1.30)$ & 0.60 & & \\
\hline Post vs Pre & & & & \\
\hline
\end{tabular}




\begin{tabular}{|c|c|c|c|c|}
\hline Factors & Univariate Analysis & p-value & Multivariate Analysis & p-value \\
\hline $\begin{array}{l}\text { Grade } \\
\text { III vs I-II }\end{array}$ & $1.73(1.15-0.62)$ & 0.01 & $1.30(0.82-2.05)$ & 0.27 \\
\hline $\begin{array}{l}\text { ER positivity(\%) } \\
\geq 90 \text { vs }<90\end{array}$ & $0.66(0.45-0.98)$ & 0.04 & $0.52(0.23-1.19)$ & 0.12 \\
\hline $\begin{array}{l}\text { PR status } \\
\text { Pos vs Neg }\end{array}$ & $0.76(0.47-1.24)$ & 0.27 & & \\
\hline $\begin{array}{l}\text { Ki67 positivity(\%) } \\
\geq 20 \text { vs }<20\end{array}$ & $1.71(1.20-2.45)$ & $<0.01$ & $1.47(0.93-2.34)$ & 0.10 \\
\hline $\begin{array}{l}\text { pT } \\
2-4 \text { vs } 1\end{array}$ & $2.19(1.54-3.13)$ & $<0.01$ & $1.39(0.91-2.11)$ & 0.13 \\
\hline $\begin{array}{l}\mathrm{pN} \\
\geq 1 \text { vs } 0\end{array}$ & $1.15(0.70-1.91)$ & 0.58 & $1.20(0.68-2.10)$ & 0.53 \\
\hline $\begin{array}{l}\text { RS } \\
>30 \text { vs } \leq 30\end{array}$ & $1.47(1.02-2.12)$ & 0.04 & $0.86(0.49-1.52)$ & 0.60 \\
\hline $\begin{array}{l}\text { Chemotherapy } \\
\text { No vs Yes }\end{array}$ & $1.44(1.00-2.06)$ & 0.05 & $1.13(0.70-1.81)$ & 0.62 \\
\hline
\end{tabular}

\section{The distribution of genetic risks and gene expression between HER2 negative and HER2-low subgroups}

We compared the expression of individual RS genes between HER2 low and negative groups. The results showed no significant difference of gene expression except for HER2 gene. The level of HER2 gene mRNA was slightly higher in HER2 low subgroup than in HER2 negative one (Fig. 2).

\section{The impact of RS modules on DFS according to HER2 status}

We further evaluated the predictive roles of separate RS modules and genes in patients according to HER2 status and observed different patterns (Table 4). 


\begin{tabular}{|c|c|c|c|c|c|}
\hline Factors & HER2-negative & $p$-value & HER2-low & $p$-value & $\mathrm{p}_{\text {interaction }}$ \\
\hline \multicolumn{6}{|l|}{ ER Module } \\
\hline ER & $1.20(0.88-1.65)$ & 0.25 & $1.01(0.85-1.19)$ & 0.95 & 0.36 \\
\hline $\mathrm{PgR}$ & $0.84(0.67-1.06)$ & 0.15 & $0.97(0.87-1.08)$ & 0.55 & 0.30 \\
\hline Bcl2 & $0.88(0.58-1.32)$ & 0.53 & $0.87(0.71-1.06)$ & 0.16 & 0.67 \\
\hline SCUBE2 & $0.89(0.70-1.13)$ & 0.34 & $0.97(0.86-1.09)$ & 0.56 & 0.39 \\
\hline ER Module & $0.84(0.58-1.21)$ & 0.34 & $0.92(0.76-1.11)$ & 0.38 & 0.52 \\
\hline \multicolumn{6}{|c|}{ Proliferation Module } \\
\hline Ki67 & $2.20(1.46-3.30)$ & $<0.01$ & $1.02(0.88-1.19)$ & 0.80 & $<0.01$ \\
\hline STK15 & $1.85(1.26-2.72)$ & $<0.01$ & $1.02(0.89-1.17)$ & 0.78 & $<0.01$ \\
\hline Survivin & $1.72(1.25-2.37)$ & $<0.01$ & $1.06(0.89-1.26)$ & 0.53 & 0.03 \\
\hline CCNB1 & $1.48(0.90-2.44)$ & 0.12 & $1.19(0.95-1.50)$ & 0.14 & 0.64 \\
\hline MYBL2 & $1.52(1.15-2.02)$ & $<0.01$ & $1.08(0.90-1.28)$ & 0.41 & 0.12 \\
\hline Prol Module & 7.22(2.49-20.93) & $<0.01$ & $0.81(0.40-1.66)$ & 0.57 & $<0.01$ \\
\hline \multicolumn{6}{|l|}{ HER2 Module } \\
\hline GRB7 & $1.39(1.04-1.87)$ & 0.03 & $1.01(0.82-1.24)$ & 0.92 & 0.27 \\
\hline HER2 & $1.02(0.70-1.49)$ & 0.91 & $0.99(0.81-1.23)$ & 0.98 & 0.76 \\
\hline HER2 Module & $1.32(0.71-2.48)$ & 0.38 & $1.89(1.02-3.48)$ & 0.04 & 0.32 \\
\hline \multicolumn{6}{|c|}{ Invasion Module } \\
\hline MMP11 & $1.11(0.83-1.48)$ & 0.49 & $1.20(1.04-1.39)$ & 0.02 & 0.53 \\
\hline CTSL2 & $1.39(1.06-1.83)$ & 0.02 & $1.08(0.90-1.29)$ & 0.42 & 0.30 \\
\hline Inv Module & $1.58(1.04-2.38)$ & 0.03 & $1.30(1.05-1.61)$ & 0.02 & 0.68 \\
\hline GSTM1 & $1.15(0.82-1.62)$ & 0.43 & $0.85(0.70-1.02)$ & 0.08 & 0.32 \\
\hline CD68 & $1.57(1.02-2.41)$ & 0.04 & $1.02(0.80-1.30)$ & 0.87 & 0.20 \\
\hline BAG1 & $1.13(0.73-1.77)$ & 0.58 & $1.01(0.82-1.24)$ & 0.96 & 0.99 \\
\hline
\end{tabular}

In HER2 negative subgroup, most of the proliferation related genes played important parts in predicting DFS, as well as the whole module. Although GRB7 in HER2 module acted as a possible predictor of 
poorer survival (hazard ratio $=1.39,95 \% \mathrm{Cl} 1.04-1.87, \mathrm{p}=0.03$ ), HER2 mRNA expression and HER2 module didn't had significant prognostic value. The increased invasion module score was also associated with worse survival outcome. No significance was association was found between ER module and DFS.

In HER2 low subgroup, the proliferation related genes lost prognostic value. In addition, unlike in the HER2 negative subgroup, the higher score of HER2 module might predict increased risk of DFS events (hazard ratio $=1.89,95 \% \mathrm{Cl} 1.02-3.48, \mathrm{p}=0.04)$. The invasion module still served as a negative prognostic factor, while the correlation between ER related genes and DFS was not obvious in HER2 low as in HER2 negative patients.

The interaction test for HER2 status and proliferation module showed that there were significant interactive effects of most proliferation related genes and HER2 status on DFS.

\section{Discussion}

Recently, the outstanding therapeutic effects of novel antibody-drug conjugates (ADCs) ${ }^{14,15}$ to HER2 low expressed breast cancer had arouse the interest in this potential new subtype. Our study compared the clinicopathological characteristics and 21-gene modules of HER2 low and HER2 negative subgroups of HR + early breast cancer. We found that the expression of HER2 had a positive correlation with ER. Although the distribution of genes and modules was almost similar between these two subgroups, the proliferation had a better performance when predicting DFS in HER2- patients than in HER2 low patients. Our results provided important suggestion for use of clinicopathological factors and 21-gene assay in HER2-low patients.

The distributions of most of basic clinical and pathological features were similar in HER2 low and negative patients. However, HER2 low breast cancer constituted a higher proportion of ER high expressed tumors compared with HER2 negative subgroup. The expression data derived from tests of 21-gene assay also showed a direct relation between HER2 and ER at the mRNA levels (supple Fig. 1). This was in consistency with the previous evidence based on HER2 negative patients ${ }^{23}$. Furthermore, this correlation was stronger in HER2-low cases than in pure HER2-negative ones (Spearman R $=0.5$ vs 0.3 ).

In the analysis of survival outcomes, we noticed the possible protective effect of high ER expression ${ }^{24,25}$, which was observed in plenty of studies. The Kaplan-Meier Curve showed no significant difference was found between HER2 low and negative patients. As a whole, despite that some of the previous findings demonstrated that moderate HER2 expression might be an unfavorable prognostic factor for survival outcome ${ }^{9,26}$, our study showed that HER2 status (low/negative) couldn't be routinely used as an independent prognostic factor in $\mathrm{HR}+$ breast cancer patients. Two recent studies also discovered that HER2-low/HR + patients had similar survival outcomes compared with HER2-/HR + patients. Furthermore, a recent research based on PAM50 subtype demonstrated that instead of low HER2 expression, it was hormone receptor and its related genes expression that might be the actually dominated oncological 
driver for HER2-low/HR + breast cancer ${ }^{10}$. This subtype was found to make up for a dominated proportion of luminal A/B breast cancer in current data. In addition, our study found its strong correlation with high ER expression, which corresponded to the hypothesis above.

The 21-gene test was one of the most widely accepted assay for making treatment strategies in HR + breast cancer patients and the HER2-related module was an important part of 21 gene assay. As expected, the expression of HER2 was higher in HER2 low patients than in HER2 negative patients. Higher HER2 module also had an association with poor DFS in HER2 low patients, while we failed to find any predictive value of HER2 gene expression in HER2- group. Of note, almost all of the proliferation related genes were strong unfavorable prognostic factors only in HER2 negative patients. However, these factors had no significant predictive value in HER2 low patients. Further analysis for interaction confirmed that most of proliferation related genes, as well as the whole module, had different prognostic value with HER2 status changed. An implication of this difference was that the recurrence score might somewhat amplify the impact of proliferation related genes in HER2 low breast cancer.

We conducted survival analysis using RS cutoff points of 18 and 30 in HER2 negative and low patients respectively to test whether the RS range maintained its prognostic value in HR + patients regardless of HER2 status. The Kaplan-Meier curve of HER2 negative patients was in concordance with previous results, which suggested that RS had a good performance as a DFS predictor in this cohort. Meanwhile, when focusing on HER2 low patients, we noticed that no significant difference was found between these three subgroups. Further STEPP analysis showed an obvious survival disparity between HER2 low and negative patients with RS $>30$. It should be pointed out that the corresponding coefficient of proliferation module was the highest among the four modules in the RS algorithm ${ }^{18}$. We hypothesized that the 21gene assay was more applicable to HR+/HER2- patients than to HR+/HER2-low patients since the proliferation module contributed predominantly to the recurrence score while its predictive value actually varied according to different HER2 status. A stricter range of RS might compensate for the absence of proliferation related predictability in HER2 low breast cancer.

Our study had several limitations. First, we conducted our study based on retrospective data which meant that potential bias was unavoidable. Secondly, the follow-up time of our patients might be not long enough for HR + breast cancer. We also limited our analysis to basic molecular subtypes and the 21-gene assay. It might be better to incorporate the PAM50 subtypes. In addition, in subpopulation analysis, we used 18 and 30 as cutoff points of RS because the majority of our patients was diagnosed and treated before the $11 / 25$ cutoff point from the TAILORx study 27 .

\section{Conclusion}

In conclusion, our study found that HER2 low expression couldn't be used an individual prognostic factor in HR + patients. HER2-low patients had a higher proportion of ER high expressed tumors than HER2 negative ones did. The 21-gene assay and its proliferation module might be less applicable to HER2-low patients compared with HER2 negative patients, which should be noticed in clinical practice.

Page $12 / 19$ 


\section{Declarations}

Ethics approval and consent to participate: NA

Funding: NA

Consent for publication: Written informed consent for publication was obtained from all participants.

Acknowledgements: We appreciate all the patients for their participation and study coordinators, nurses, and physicians for their assistance.

Author Contributions:

LZ, JY and MC made study design. DL, WC and KS participated in data acquisition. JW and MC conducted statistical analysis and manuscript preparation. KS and LZ helped to review the manuscript. All authors read and approved the final manuscript.

Competing Interests statement: The authors disclose that no financial support has been received from any person or organization for this study.

Availability of supporting data: The data used to support the findings of this study are available from the corresponding author upon request.

\section{References}

1. Cameron D, Piccart-Gebhart MJ, Gelber RD, et al. 11 years' follow-up of trastuzumab after adjuvant chemotherapy in HER2-positive early breast cancer: final analysis of the HERceptin Adjuvant (HERA) trial. Lancet. 2017;389(10075):1195-1205.doi:10.1016/S0140-6736(16)32616-2

2. von Minckwitz G, Procter M, de Azambuja E, et al. Adjuvant Pertuzumab and Trastuzumab in Early HER2-Positive Breast Cancer. N Engl J Med. 2017;377(2):122-131.doi:10.1056/NEJMoa1703643

3. Johnston SRD, Hegg R, Im SA, et al. Phase III, Randomized Study of Dual Human Epidermal Growth Factor Receptor 2 (HER2) Blockade With Lapatinib Plus Trastuzumab in Combination With an Aromatase Inhibitor in Postmenopausal Women With HER2-Positive, Hormone Receptor-Positive Metastatic Breast Cancer: ALTERNATIVE. J Clin Oncol. 2018;36(8):741-

748.doi:10.1200/JC0.2017.74.7824

4. Lee HJ, Kim JY, Park SY, et al. Clinicopathologic Significance of the Intratumoral Heterogeneity of HER2 Gene Amplification in HER2-Positive Breast Cancer Patients Treated With Adjuvant Trastuzumab. Am J Clin Pathol. 2015;144(4):570-578.doi:10.1309/AJCP51HCGPOPWSCY

5. Kurozumi S, Padilla M, Kurosumi M, et al. HER2 intratumoral heterogeneity analyses by concurrent HER2 gene and protein assessment for the prognosis of HER2 negative invasive breast cancer patients. Breast Cancer Res Treat. 2016;158(1):99-111.doi:10.1007/s10549-016-3856-2 
6. Hou Y, Nitta H, Wei L, et al. HER2 intratumoral heterogeneity is independently associated with incomplete response to anti-HER2 neoadjuvant chemotherapy in HER2-positive breast carcinoma. Breast Cancer Res Treat. 2017;166(2):447-457.doi:10.1007/s10549-017-4453-8

7. Tarantino P, Hamilton E, Tolaney SM, et al. HER2-Low Breast Cancer: Pathological and Clinical Landscape. J Clin Oncol. 2020;38(17):1951-1962.doi:10.1200/JC0.19.02488

8. Schalper KA, Kumar S, Hui P, Rimm DL, Gershkovich P. A retrospective population-based comparison of HER2 immunohistochemistry and fluorescence in situ hybridization in breast carcinomas: impact of 2007 American Society of Clinical Oncology/College of American Pathologists criteria. Arch Pathol Lab Med. 2014;138(2):213-219.doi:10.5858/arpa.2012-0617-OA

9. Eggemann $\mathrm{H}$, Ignatov $\mathrm{T}$, Burger $\mathrm{E}$, et al. Moderate HER2 expression as a prognostic factor in hormone receptor positive breast cancer. Endocr Relat Cancer. 2015;22(5):725-733.doi:10.1530/ERC-15-0335

10. Agostinetto E, Rediti M, Fimereli D, et al. HER2-Low Breast Cancer: Molecular Characteristics and Prognosis. Cancers (Basel). 2021;13(11).doi:10.3390/cancers13112824

11. Schettini F, Chic N, Braso-Maristany F, et al. Clinical, pathological, and PAM50 gene expression features of HER2-Iow breast cancer. NPJ Breast Cancer. 2021;7(1):1.doi:10.1038/s41523-020-002082

12. Kim MH, Kim GM, Kim JH, et al. Intermediate HER2 expression is associated with poor prognosis in estrogen receptor-positive breast cancer patients aged 55 years and older. Breast Cancer Res Treat. 2020;179(3):687-697.doi:10.1007/s10549-019-05505-4

13. Fehrenbacher L, Cecchini RS, Geyer CE, Jr., et al. NSABP B-47/NRG Oncology Phase III Randomized Trial Comparing Adjuvant Chemotherapy With or Without Trastuzumab in High-Risk Invasive Breast Cancer Negative for HER2 by FISH and With IHC 1+ or 2. J Clin Oncol. 2020;38(5):444453.doi:10.1200/JC0.19.01455

14. Modi S, Park H, Murthy RK, et al. Antitumor Activity and Safety of Trastuzumab Deruxtecan in Patients With HER2-Low-Expressing Advanced Breast Cancer: Results From a Phase Ib Study. J Clin Oncol. 2020;38(17):1887-1896.doi:10.1200/JC0.19.02318

15. Banerji U, van Herpen CML, Saura C, et al. Trastuzumab duocarmazine in locally advanced and metastatic solid tumours and HER2-expressing breast cancer: a phase 1 dose-escalation and doseexpansion study. Lancet Oncol. 2019;20(8):1124-1135.doi:10.1016/S1470-2045(19)30328-6

16. van der Lee MM, Groothuis PG, Ubink R, et al. The Preclinical Profile of the Duocarmycin-Based HER2-Targeting ADC SYD985 Predicts for Clinical Benefit in Low HER2-Expressing Breast Cancers. Mol Cancer Ther. 2015;14(3):692-703.doi:10.1158/1535-7163.MCT-14-0881-T

17. Denkert C, Seither F, Schneeweiss A, et al. Clinical and molecular characteristics of HER2-low-positive breast cancer: pooled analysis of individual patient data from four prospective, neoadjuvant clinical trials. Lancet Oncol. 2021.doi:10.1016/S1470-2045(21)00301-6

18. Paik S, Shak S, Tang G, et al. A multigene assay to predict recurrence of tamoxifen-treated, nodenegative breast cancer. N Engl J Med. 2004;351(27):2817-2826.doi:10.1056/NEJMoa041588 
19. Hammond ME, Hayes DF, Dowsett M, et al. American Society of Clinical Oncology/College Of American Pathologists guideline recommendations for immunohistochemical testing of estrogen and progesterone receptors in breast cancer. J Clin Oncol. 2010;28(16):27842795.doi:10.1200/JC0.2009.25.6529

20. Wolff AC, Hammond MEH, Allison KH, et al. Human Epidermal Growth Factor Receptor 2 Testing in Breast Cancer: American Society of Clinical Oncology/College of American Pathologists Clinical Practice Guideline Focused Update. J Clin Oncol. 2018;36(20):21052122.doi:10.1200/JC0.2018.77.8738

21. Lin C, Wu J, Lin L, et al. A Novel Prognostic Scoring System Integrating Gene Expressions and Clinicopathological Characteristics to Predict Very Early Relapse in Node-Negative Estrogen ReceptorPositive/HER2-Negative Breast Cancer. Front Oncol. 2020;10:1335.doi:10.3389/fonc.2020.01335

22. Lazar AA, Cole BF, Bonetti M, Gelber RD. Evaluation of treatment-effect heterogeneity using biomarkers measured on a continuous scale: subpopulation treatment effect pattern plot. $J$ Clin Oncol. 2010;28(29):4539-4544.doi:10.1200/JC0.2009.27.9182

23. Pinhel I, Hills M, Drury S, et al. ER and HER2 expression are positively correlated in HER2 nonoverexpressing breast cancer. Breast Cancer Res. 2012;14(2):R46.doi:10.1186/bcr3145

24. Ma H, Lu Y, Marchbanks PA, et al. Quantitative measures of estrogen receptor expression in relation to breast cancer-specific mortality risk among white women and black women. Breast Cancer Res. 2013;15(5):R90.doi:10.1186/bcr3486

25. Bartlett JM, Brookes CL, Robson T, et al. Estrogen receptor and progesterone receptor as predictive biomarkers of response to endocrine therapy: a prospectively powered pathology study in the Tamoxifen and Exemestane Adjuvant Multinational trial. J Clin Oncol. 2011;29(12):15311538.doi:10.1200/JC0.2010.30.3677

26. Rossi V, Sarotto I, Maggiorotto F, et al. Moderate immunohistochemical expression of HER-2 (2+) without HER-2 gene amplification is a negative prognostic factor in early breast cancer. Oncologist. 2012;17(11):1418-1425.doi:10.1634/theoncologist.2012-0194

27. Sparano JA, Gray RJ, Makower DF, et al. Adjuvant Chemotherapy Guided by a 21-Gene Expression Assay in Breast Cancer. N Engl J Med. 2018;379(2):111-121.doi:10.1056/NEJMoa1804710

\section{Figures}



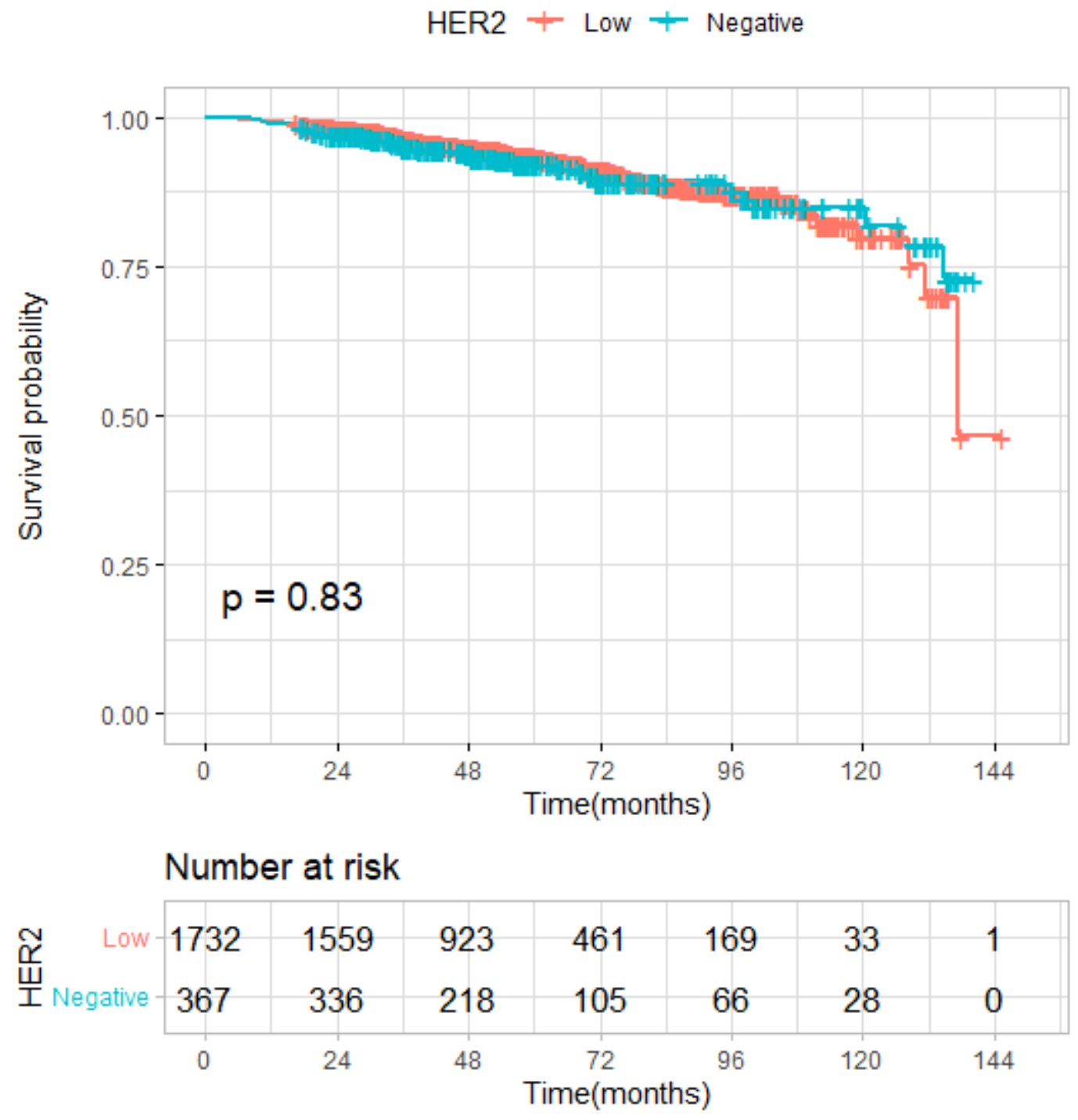

Figure 1

Association between HER2 status and DFS in HR+ breast cancer patients. 

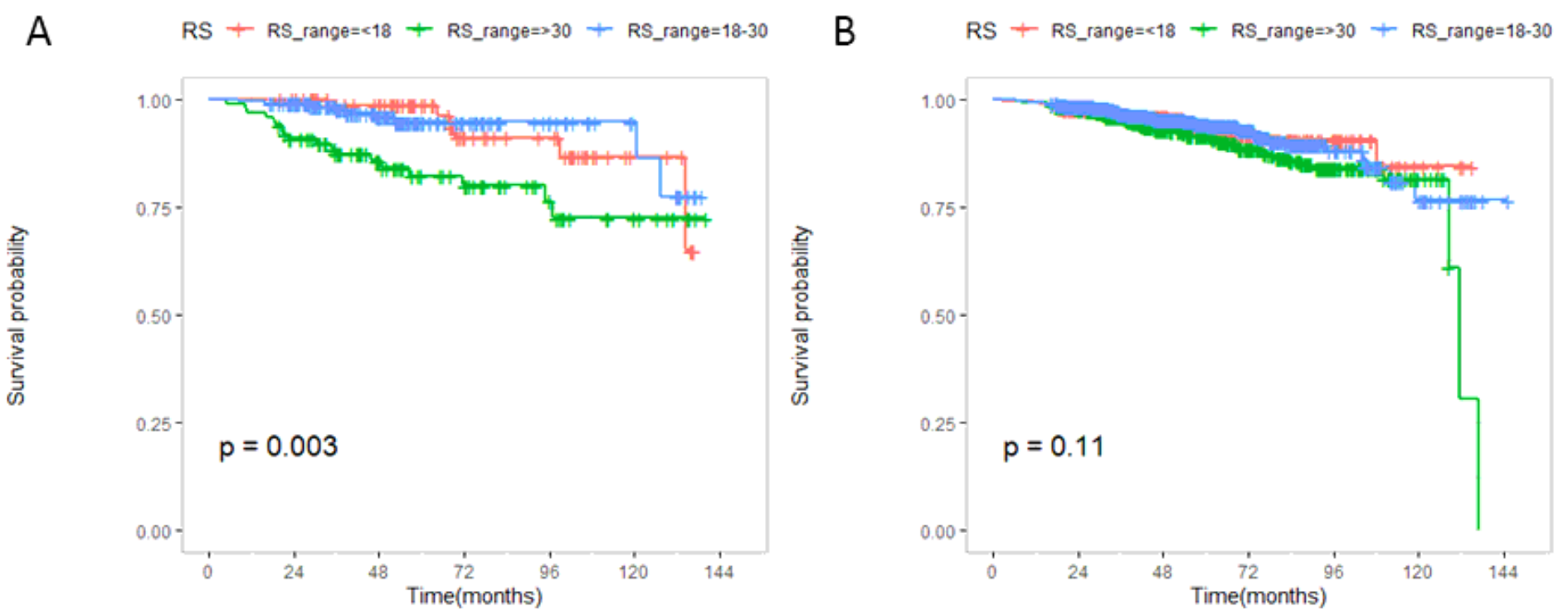

\begin{tabular}{|c|c|c|c|c|c|c|c|}
\hline \multirow{5}{*}{ 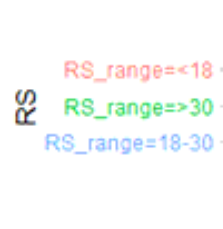 } & \multicolumn{7}{|c|}{ Number at risk } \\
\hline & 83 & 81 & 63 & 31 & 23 & 6 & 0 \\
\hline & 99 & 86 & 54 & 35 & 21 & 11 & 0 \\
\hline & 185 & 169 & 101 & 39 & 22 & 11 & 0 \\
\hline & 0 & 24 & 48 & $\begin{array}{l}72 \\
\mathrm{e}(\mathrm{m}\end{array}$ & s) & 120 & 144 \\
\hline
\end{tabular}

\begin{tabular}{|c|c|c|c|c|c|c|c|}
\hline & \multicolumn{7}{|c|}{ Number at risk } \\
\hline RS_range $=<18$ & 361 & 323 & 213 & 85 & 36 & 5 & 0 \\
\hline RS_range $=>30$ & 457 & 416 & 271 & 186 & 75 & 11 & 0 \\
\hline RS_range $=18-30$ & 914 & 820 & 439 & 190 & 58 & 17 & 1 \\
\hline & 0 & 24 & 48 & 72 & 96 & 120 & 144 \\
\hline
\end{tabular}

Figure 2

DFS of patients with different genetic risks in HER2 negative (A) and low (B) subgroups.

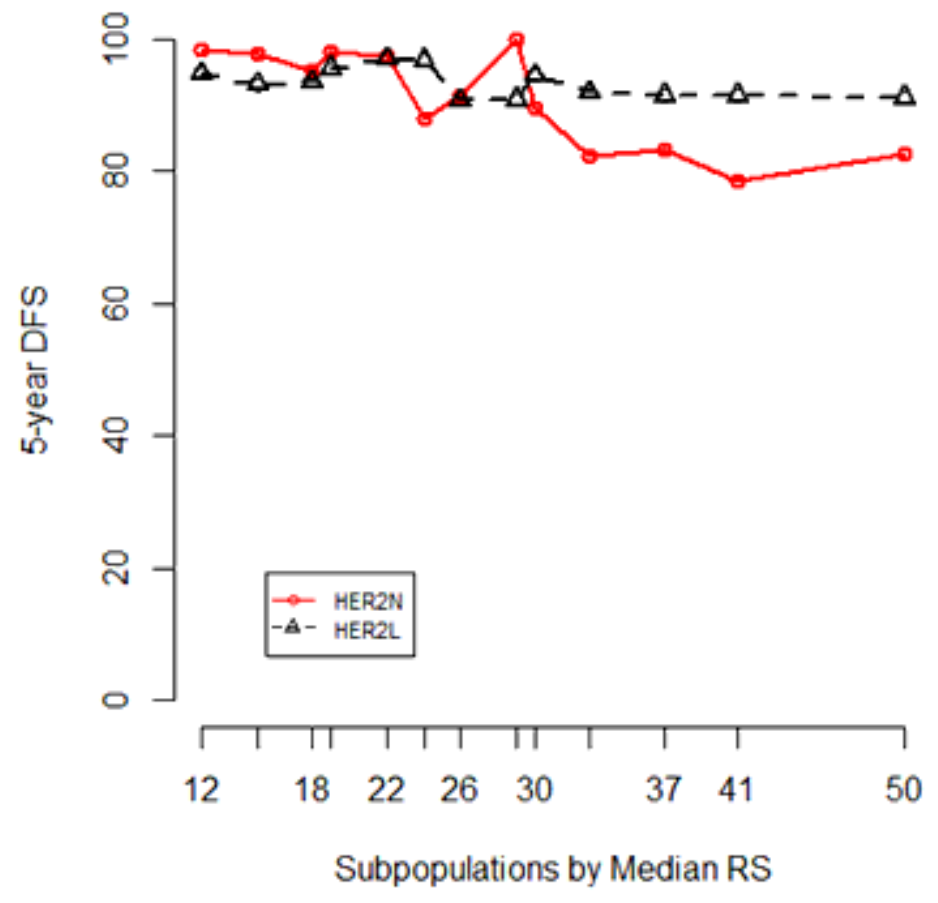

\section{Figure 3}

5-year DFS of subpopulation with different HER2 status by median RS 

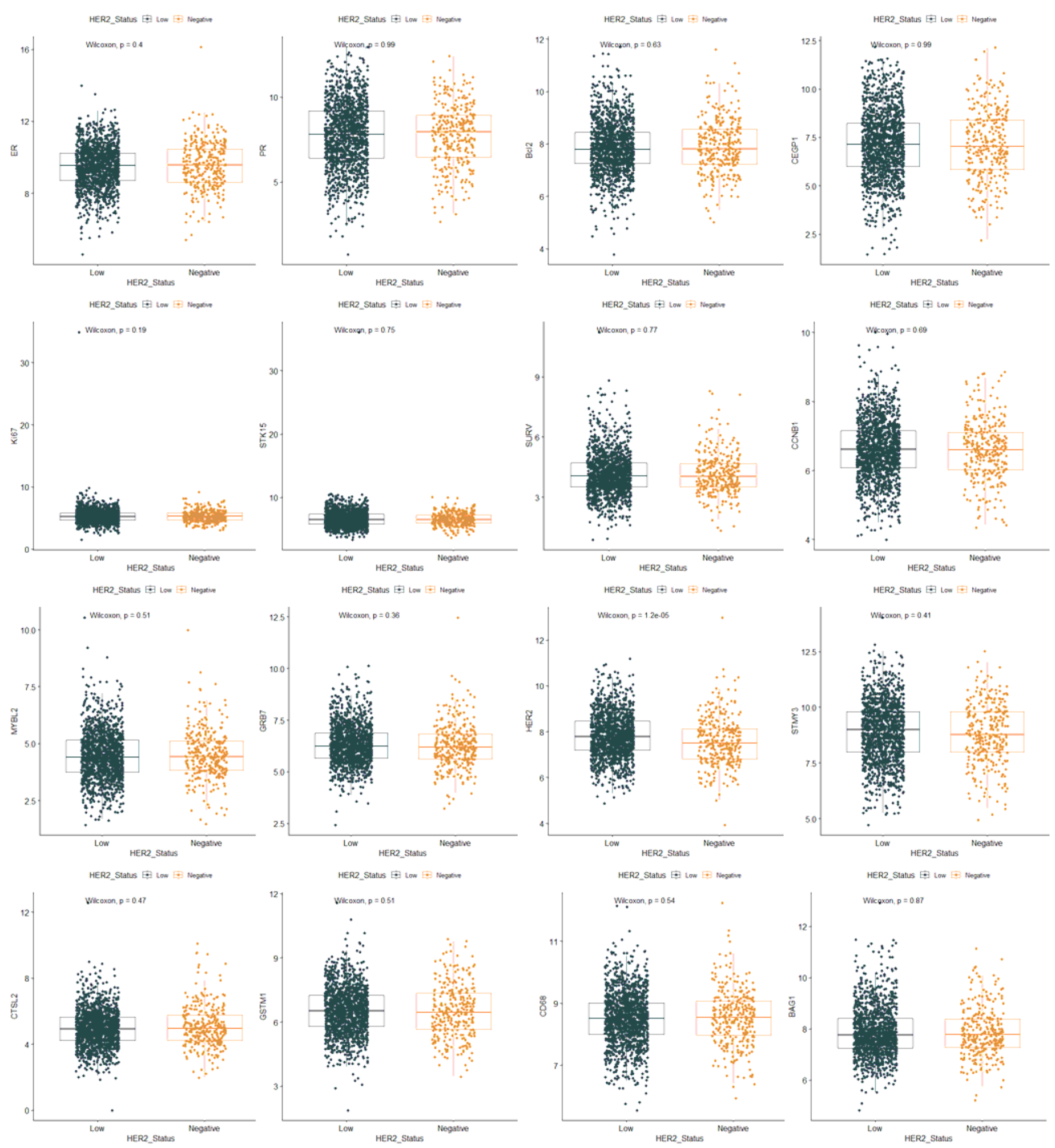

\section{Figure 4}

The expression of RS genes in HER2 low and negative subgroup respectively.

\section{Supplementary Files}

This is a list of supplementary files associated with this preprint. Click to download. 
- $\quad$ supfig1.tif

Page 19/19 